\title{
Discussion.
}

The President. The President moved a vote of thanks to the Author for his Paper.

The Author. The Autror remarked that Fig. 3 had been prepared in the first instance to show clearly the flows measured with a single main up to each cross-over, and double main beyond. In the Paper he had mentioned that it was immaterial where the single main was, and whether it was in one or more pieces; but he had not shown any justification for that statement. He had, therefore, had open circles put on Fig. 3, which indicated flows obtained in lengths of single main situated at different points on the Severn siphon but plotted from the inlet. Two of them coincided with the curve; two which were below it were from steel pipes situated at about the middle of the siphon, and tended to prove the statement in the Paper that the irregularity in the curve was due to the steel pipes being more corroded than the cast-iron. The open circle at 59,000 feet showed the flow which was obtained through four separate lengths of single main situated on different portions of the siphon, with lengths of double main between, so that for those to come into operation the water had to pass through seven cross-overs. This practically coincided with the curve, proving that the loss of head at each cross-over was not serious. Turning to Fig. 6 , taking any fixed proportion of length on the siphons, it would be found that on each siphon there was practically the same discharge, making allowance for slight difference in their individual efficiency. Fig. 7 applied to the laying of a new main and emphasized the point that the longer the total length laid, the shorter were the individual lengths required to give a unit of increase. To get an increase of $2 \mathrm{~m} . g . d$. from 12 to $14 \mathrm{~m}$.g.d. a length of about 12,000 feet would have to be laid; but for a similar increase from 18 to 20 millions, it was only necessary to lay 4,000 feet. That was of particular value in conjunction with the fact that the additional main could be laid in short lengths on different parts of the siphon, and, therefore, it was possible to start with the cheapest lengths.

Dr. Bright- Dr. A. W. BRightmone considered the Paper very appropriate at more. the present time, as it indicated in a particular case how to apportion expenditure to the results immediately required. Although the principles involved had been well understood from the hydraulic point of view, no one appeared to have thought of putting them. 
into practice until the particular conditions under which the Author Dr. Brightwas working with the object of maintaining the supply of water to more.

Birmingham during repairs, forced them upon his notice. It appeared to him that the chief innovations were, first, the laying of a duplicate main in short lengths, only so much being laid as was necessary to provide the additional supply required for the time being; and, second, but equally important, the introduction of frequent cross-overs between the mains, so that a section could be isolated without materially interfering with the supply. The great advantage of the short lengths was that they could be laid at any selected points. There was one restriction, however-in which he thought the Author would probably agree with him-namely, that if a section of the pipe-line approached the hydraulic gradient of the single pipe it would be better to lay the additional pipe above that point. By being able to lay the lengths at any portion of the pipe, it was possible to lay the cheapest portions first. That might appear to lead to leaving the greater expenditure to the end ; but the Author had already emphasized the point shown by the diagrams, that the first 10,000 feet of the new pipe only increased the supply by something less than 1 m.g.d., whereas the final 10,000 feet increased it by about $4 \mathrm{~m} . \mathrm{g} . \mathrm{d}$; so that counteracted the additional cost of the more expensive part of the pipe that would probably be left until the end. With regard to the cross-overs, it was quite clear that the amount of interference with the supply could be reduced in proportion to the number of crossovers provided. With regard to the method of calculating the supply of one pipe and the portion of the second pipe adopted in the Paper, that had been done by calculating very accurately the discharge of a new pipe and then deducting from it 30 per cent. to allow for corrosion, ete., in the pipe after use for some years. That seemed to be a somewhat arbitrary method, and it might be supplemented by another, namely, direct calculation of the discharge of a pipe wbich had been in use for some years and had become coated with deposit, etc. There was a simple formula for the discharge of a pipe which had been in use for some years, namely, that the discharge of the pipe in cubic feet per minute was equal to the diameter in inches squared for a hydraulic gradient of one divided by twenty times the diameter in inches. For any other gradient it was only necessary to multiply or divide, as the case might be, by the square root of the ratio of the gradients. To show how that compared with the calculation in the Appendix, the size of pipe there was 42 inches; 42 squared gave 1704 cubic feet per minute for a gradient of $1 / 20 \times 42=1 / 840$. The

[THE INST. C.E. VOL. CCXI.] 

Dr. Bright- gradient in Table I of the Appendix was $25 / 50,000$, or $1 / 2,000$.
more. The ratio of 2,000 to 840 was $2 \cdot 38$, and the square root of $2 \cdot 38$ was $1 \cdot 54$. Dividing 1764 cubic feet per minute by $1 \cdot 54$ gave 1,150 cubic feet per minute, or 10,300,000 gallons per day, which was not very far from the figure given in the Table. The length of second main required for a particular discharge, e.g., 12 m.g.d., by the method used in the Paper, would be 17,812 feet, and by the method he had referred to it would be 18,000 feet. In the last line but one of the Table the length of main required for a discharge of 18 million gallons was given as 44,930 feet, and calculated by the method he had mentioned it was 45,000 feet; for the other discharge given in the Table, the differences were only of the same order of magnitude. 'That showed that at all events for preliminary purposes a much simpler method might be used for calculating the results. He did not wish to suggest, however, that that method was of universal application; for instance, it could not be applied without some correction to the large pipe the Author was now proposing to lay.

Professor Lea. Professor F. C. Les had been reminded by Dr. Brightmore that the Paper showed an important application of what Dr. Unwin had taught many students years ago as a sound principle in hydraulics. The Author was to be congratulated on having had the courage to make such an interesting application of it. The Author had not referred to the fact that certain losses might occur at the cross connections. They could be reduced to the minimum by having the pipes expanding or diminishing gradually, and by introducing specially large valves, but he did not think that was necessary. He had been making some calculations of the effect on the Author's curve (Fig. 3) of taking into account the possible losses due to change of section, and he would send the equations ${ }^{1}$ later on. It

${ }^{1}$ Let $\mathrm{AB}$ and $\mathrm{CD}$, Fig. 1 a, be parallel mains and $\mathrm{BE}$ a single main, all of diameter $D$ feet, $\mathrm{AI}$ and $\mathrm{CD}$ being connected by cross connections.

Fig. 1a.

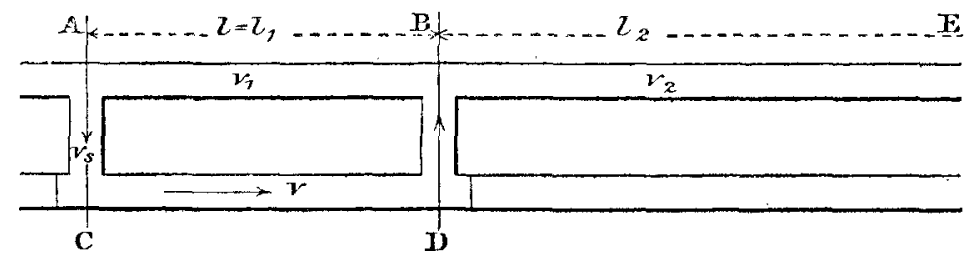

Let $v_{1}, v$ and $v_{2}$ be the velocities in these mains, respectively. Let the losses due to friction and shock be assumed proportional to the square of 
was interesting to find that, if in a length of 50,000 feet there was Professor Lea. a single main 30,000 feet long, and two mains for 20,000 feet, the cross connections certainly could not have an effect of more than 2 per cent. on the flow, assuming the maximum losses that were likely to occur in the cross connections. In any case he thought the cross connections were not likely to have any serious effect upon the Author's curve. Dr. Brightmore had mentioned another important point-that it was possible to lay the cheapest sections of the mains first and to increase the flow accordingly. For instance, in the Severn siphon the difference of level between the top and the bottom was about 500 feet, and to lay a mile of main at the top of the siphon where the pressures were small would obviously be much

the velocity; this is not quite true, or quite consistent with the more elaborate assumptions made by the Author in Appendix I, but it is near enough for comparative purposes. Then the loss of head between $A$ and $B$ in the pipe $A B$ is

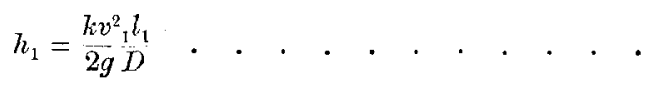

The loss of head $h_{g}$ in the cross connections, which are short, will be due to the contractions and enlargements. Let $d$ be the diameter of the cross connections. Assuming no bell-mouthed connections the loss $h_{s}$ will be very approximately

$$
h_{8}=\frac{3 D^{4}}{d^{4}} \frac{v^{2}}{2 g}
$$

the loss at entrance to each cross connection being approximately $\frac{0 \cdot 5 v^{2} s}{2 g}$ and at exit $\frac{v^{2} s}{2 g}$.

The loss of head between A and B, by the paths ACDB, is

$$
h=h_{1}=\frac{k v^{2} l}{2 g D}+\frac{3 D^{4}}{l^{5}} \frac{v^{2}}{2 g} \text {. . . . . . . . }
$$

The value of $k$ will be about 0.02 to 0.04 .

Equating (1) and (2)

or

$$
\begin{aligned}
& v_{1}^{2}=v^{2}\left(1+\frac{3 D^{5}}{l \bar{k} d^{4}}\right), \\
& v_{1}=v \sqrt{1+\frac{3 D^{5}}{l k d^{4}}}
\end{aligned}
$$

The loss of head $\quad h_{2}=\frac{k l_{2}\left(v+v_{1}\right)^{2}}{2 g i j}$ 
Proiessor Lca. cheaper than to lay a mile of main at the bottom, where the pressure-head was about 500 feet, and stronger mains were required. Referring to Fig. 7, by laying a main two-fifths the length of the whole siphon the flow would be increased by a certain amount, but if the length were increased by putting an extra length of the same amount later, the flow would be increased by a larger amount. Evidently the return on the cost of the first length laid was not so great as the return on the cost of the second. In Fig. 7 a straight line drawn between the points representing discharges of 10 and $20 \mathrm{~m} . g$.d., would probably represent, fairly accurately at all events, the cost of laying the several lengths of second main, which would be very nearly proportional-except where there were special difficulties-to the length laid. The capital outlay was not so eflicient in the first

Now let $H$ be the total head available between $\mathrm{A}$ and $\mathrm{E}$, and let $L$ be the total length $\mathrm{AE}$. Let

and

$$
l=n L, \text { then } l_{2}=(1-n) L,
$$

$H=\frac{k L v^{2}}{2 g D}\left\{(1-n)\left[1+\sqrt{1+\frac{3 D^{5}}{k n L d^{4}}}\right]^{2}+n\left(1+\frac{3 D^{5}}{k n L d^{4}}\right)\right\} .$.

from which $v$ can be calculated. The total discharge is $\left(v+v_{1}\right) A$ where $A$ is the area $\frac{\pi}{4} D^{2}$ of one pipe.

If the loss through the cross connections be neglected,

$$
v=v_{1}=\sqrt{\frac{2 g H D}{k L}} \frac{1}{\sqrt{4-3 n}}
$$

Let $D=40$ inches, $d=18$ inches, and $k=0 \cdot 02$.

Let $L=50,000$ feet and $l=20,000$ feet, i.e., $n=\frac{2}{5}$ and $(1-n)=\frac{3}{5}$

Neglecting the losses in the cross connections,

$$
v=\frac{1}{\sqrt{2 \cdot \overline{8}}} \sqrt{\frac{\overline{2 g H \bar{D}}}{k L}}=0 \cdot 6 \frac{2 g H D}{k L} \text { very nearly, }
$$

and the total discharge is $1.2 Q$, where $Q$ is the discharge through a single pipe. That is an expenditure of 40 per cent. of the cost of the single pipe-line increases the discharge by 20 per cent.

From equation (3)

or

$$
\begin{aligned}
& H=\frac{k L v^{2}}{2 g D}\{2 \cdot 814\}, \\
& v=\frac{1}{\sqrt{2} \cdot 814} \sqrt{\frac{2 g H D}{K L}},
\end{aligned}
$$

i.e., the discharge differs from that previously obtained by less than 1 per cent. 
lengths laid as in the later lengths, but still it was capital expended Professor Lea. economically, because it increased the capacity of the whole system. ${ }^{1}$

Mr. H. J. Trivess Smith observed that the Paper was of great Mr. Smith. interest to him as he happened to be connected with a water-supply having very similar features to those described. About 9 years ago he was asked to increase the water-supply to Bombay, and he did so by laying another main across the siphons connecting the aqueducts. A new 50-inch main was laid parallel to an existing 48-inch main. On the old 48 -inch main there were 48 -inch sluice-valves at intervals of 3 or 4 miles. When he laid the second main he put in 24-inch cross connections between the mains, so that in the event of a burst on either main only one section would be cut out of use. The discharge of the two mains together was about 37 million gallons per day, and when a burst occurred only one section had to be closed down. The quantity disoharged through

1 Suppose the capital charge of an original single pipe is $£ n$ per foot. Then the capital charge per unit discharge is $\frac{£ n L}{Q}$

Let a parallel length $l_{0}$ be laid at the same cost per unit, whereby the discharge is increased to $Q_{1}$. Then the extra capital charge is $£ n l_{0}$ and the cost per unit flow is

$$
\frac{£ n\left(L+l_{0}\right)}{Q_{1}}
$$

Now it has been shown that for an added parallel length $l_{0}$ of $\frac{2}{5} L$ the increased discharge was $0.2 Q$. The discharge for an added length $l_{0}$ can be expressed as

where $k$ is a fraction.

$$
Q_{1}=Q\left(1+k \frac{l_{0}}{L}\right)
$$

Then the cost per unit flow is now

$$
\frac{£ n}{Q} \frac{\left(L+l_{0}\right)}{\left(1+k \frac{l_{0}}{L}\right)}=\frac{£ n L}{Q} \frac{(1+n)}{(1+k n)}
$$

Since $n$ and $z$ are both fractions

$$
\frac{1+n}{1+k n}
$$

is greater than unity. This can be illustrated by Fig. \&a. Duplicating the pipe by a length $c a$, the discharge is increased by $a b ; a c$ is the increased cost. 
Mr smith. the two mains, with the bit cut out, was generally about $25 \mathrm{~m} . g . d$, so that there was a gain of about 7 or $8 \mathrm{~m}, \mathrm{~g}$.d. from the cross-overs.

Mr. Moore. Mr. R. St. George Moone mentioned that he had just visited the siphons of which Mr. Trivess Smith had been speaking; the adoption of cross-overs there had enabled him to report to the Bombay Corporation in favour of doing away with the present aqueduct, which was cut on hillsides, and to substitute a pipe; because with the rross-overs there was no risk of ever reducing the City of Bombay to dependence upon the limited capacity of one pipe. The principle was the same as that which the Author had described. He had first put it into practice personally in the Hankow waterworks, where

When, however, the capital charge per unit discharge through a given pipe-line, due to the pipe-line plus other works, is taken into account,

\section{Fig. \&a.}

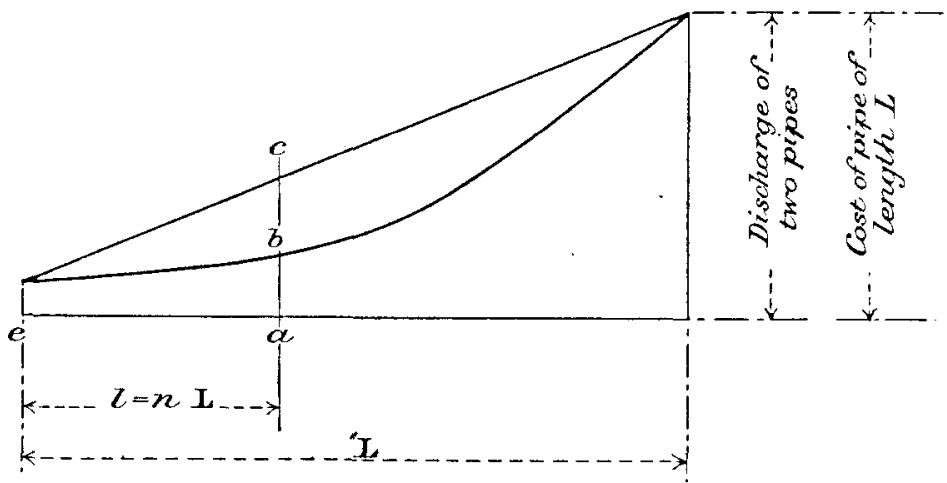

the result may be very different. Iet $m$ be the capital charge of the whole works per unit length. Then $\frac{m L}{Q}$ is the cost per unit discharge. To add a new pipe the cost per unit length $n$ will be much less than $m$ and the capital charges per unit will be now

$$
m L \frac{\left(1+\frac{n}{m}\right)}{Q_{1}(1+k n)}
$$

and since $Q_{1}$ is greater than $Q$ this will certainly be less than $\frac{m L}{Q}$ if $\begin{gathered}n \\ m\end{gathered}$ is less than $k$, and will be less than $\frac{m L}{Q}$ if

$$
\frac{1+\frac{n}{m}}{Q_{1}(1+k n)}<\frac{1}{Q_{1}}
$$


every cast-iron pipe had to be transported from England to a point Wr. Moore. 700 miles up the Yangtse river, so that economy was necessary in the use of cast-iron pipes. A large town like Hankow could not depend on one pumping-main, especially one which had to be laid in treacherous ground; he therefore adopted duplicate mains, the combined capacity of which was just sufficient; and by making cross connections about every $1 \frac{1}{4}$ mile there was only a risk of $1 \frac{1}{4}$ mile being out of service during repairs. When he left China that installation was working very successtully.

Mr. Sidnex R. Lowcock pointed out that cross connections of the $\mathrm{Mr}$. Lowcock. kind the Author had described were used in the Derwent Valley waterworks, and he believed that was the first case where they were put in and worked in the way the Elan aqueduct siphons were worked. It should be recognized that the method was due to one of Mr. Edward Sandeman's resident engineers, Mr. E. H. Whiteford, M. Inst. C.E. He did not say that in any derogation of the work the Author had done, which met in a very satisfactory way the unforeseen difficulties that had arisen in the case of Birmingham. One of the most useful things to his mind was the further development of the principle which would enable lengths of main to be put in to meet the requirements as they arose or increased. The Author said that the velocity through 6 -inch cross-overs would be undesirably high, but Mr. Lowcock was inclined to say that whatever quantity might go through a 6 -inch cross-over, it would not be worth talking about for the supply of a city like Birmingham. With regard to the question of the loss of head through the crossovers, this did not appear to be taken into account in the formula suggested. In Fig. 2 the cross-over connections were above the two outer mains, each of which was separated from the centre main by a valve. If the centre main gave way there would be no cross-over between the outside mains-except by putting two lengths between the stop valves on the main pipe-lines out of commission-unless there were valves on the main pipe-lines immediately on each side of the cross-over. But if, instead of putting the valves vertically on the branches, they were put horizontally on top of the pipes leading up from the main pipe-lines, it would save two air-valves, and would only require six sluice-valves, three on the mains and three on the cross-overs, in place of eight, six on the mains and two on the cross-overs; and any variations could be made on the combination of the three lines of pipe. With regard to Fig. 7 and the calculations on which it was based, as far as he could see the curve was practically hyperbolic, and therefore it seemed to him it would be possible to 
Mr. Lowcock. use a much simpler formula than that given in the Appendix. To have to work out two factors, one to the power, $2 \cdot 769$, and the other to the power, 0.529 , was laborious and cumbersome-and, indeed, impossible without a table of logarithms. He thought there was a much simpler way, especially in connection with a case such as that under discussion. As the diameter, the total length, and the head for the ultimate discharge of the two or more lines of pipes were decided upon, there remained only one variable in the formula. It seemed to him that by altering the coefficient slightly and working out the last factor, $i$, to the square root (power 0.5 ) of $i$, the formula could be made to answer the purpose perfectly well, especially when it was considered that, to however many places of decimals it might be worked out, 30 per cent. was allowed for incrustation. He disliked formulas that were not simple enough to be easily remembered. Most of the bases on which the calculations for the sizes of mains were founded were of necessity more or less guesswork. When an engineer proposed to supply a city or district with water, he had to estimate as nearly as possible from the available data the population to be supplied both at once and in the future, the quantity per head per day needed at once and likely to be needed in the future, and the period for which the works should provide. When all those figures had to be arrived at by processes which were liable to large percentages of error, what was the advantage of working to the power 0.529 when 0.5 would answer the purpose?

Mr. Maddocks. Mr. A. P. Mapdocks agreed with Mr. Lowcock that a point of the greatest importance was that touched upon at p. 43 in connection with the laying of a duplicate main in sections. In connection with the supply to the Metropolis, the laying of a main about 66 inches in diameter and 17 miles in length, to the north-west of London, was contemplated, but, owing to the excessive prices of materials at present, it was proposed to lay instead two mains, each about 4 feet in diameter, at a considerable interval of years. It was obvious from the Paper that if that second instalment were laid in sections at intervals of 2 or 3 years, on the lines suggested, a considerable saving, not only in capital expenditure but also in the rating of the main, would be effected. Although no doubt, as had been pointed out, there was nothing new in the principle, it was very valuable to have its application brought home in a practical way. The one criticism he wished to make related to the formula adopted by Mr. Barnes for the flow along the pipes. The Author stated that experiments had been made, but Mr. Maddocks did not gather that it had been practicable to make experiments which 
would really compare the discharge in pipes of widely different $\mathrm{Mr}$. Mraddocks. diameters. In all the formulas known to himself, such as Dr. Unwin's or the American formula of Messrs. Hazen and Williams, the power of $r$ was given generally as in the neighbourhood of 0.5 or 0.6 , or possibly $\frac{2}{3}$; but Mr. Barnes gave practically $0 \cdot 77$, and it was obvious that, as the diameter increased, the discharge of the large pipes increased very considerably according to his formula. It therefore seemed that, unless the experiments on which that formula was founded were entirely reliable, there was a serious risk of overestimation of the discharge from a 60 -inch pipe. Mr. Barnes's formula gave about $\frac{1}{7}$ more flow for a 60 -inch pipe than Dr. Unwin's formula or the American formula did, and as the diameter was further increased to 90 inches or 120 inches the discrepancy became very considerable indeed. In his opinion, based on the formulas of Dr. Unwin and others, it would not be safe to expect more than about $\frac{7}{8}$ of the flow through the 60 -inch pipe given by Mr. Barnes's formula.

Mr. S. C. Lewis remarked that to those who, like himself, had Mr. Lewis. had close connection with the water-supply of Birmingham from the Elan Valley the Paper was of particular interest. It was true, as had been said, that the hydraulic principle underlying the Author's adaptation was not new, and it was also true that the principle of cross-overs had been adopted by Mr. Sandeman on the Leicester siphon of the Derwent Valley waterworks, on the advice of Mr. Whiteford; or, at least, provision had been made for cross-overs, although Mr. Lewis was not sure that the second pipe bad been laid. The Author might fairly claim, however, to be the first to adapt the principle completely to large hydraulic mains; and he had been able to experiment on those mains and give the results in a clear and concise manner. On hearing of the crossover valves, Mr. Lewis had asked himself, what would be done with the automatic valves? The Author had frankly faced that difficulty, and had taken the legitimate risk of leaving the valves as they were. That would appear to be perfectly right, and Mr. Lewis was not sure that it would ever be wise to attempt to devise elaborate valves to get over the difficulty, because, even if all the automatic doors went down through a burst on one main, it took very little time to set them going again, compared with the loss of tine in having to discharge the main and shut off several valves. He agreed with Mr. Lowcock in his plea for a simple formula. He had made one or two experiments in producing formulas, but had always given it up in disgust, as nothing came out as simple as he wished. 
The Author. The Aurnor, in reply, expressed his thanks for the kind reception of his Paper. He wished first to disarm a certain kind of criticism which had appeared in one or two quarters. All he desired was to publish what he had done, without any claim to originality. $\mathrm{He}$ quite saw the point Dr. Brightmore had made, and understood the risk run of pulling the hydraulic gradient below summits on a long siphon. This, however, could be avoided. With regard to Dr. Brightmore's formula, he had gone into it a little, with the assistance of his staff, and it did not appear to him to fit universally. It fitted the 40-inch or 42-inch pipe, but it did not appear to be accurate for other diameters. With reference to Professor Lea's remarks, the loss of the head at the cross connections could be worked out theoretically, and for the Elan aqueduct it had been estimated at as much as 4 feet at each cross connection; but, from observations of the cross connections that had been installed, he did not think there was anything as great as that actually. From one or two small tests that had been made, he believed that the loss was more like 18 inches, but he did not give that as a definite figure. It had been arrived at by means of pressure-gauges, and they were not always reliable. In the case of a siphon like the Severn siphon, where there was a fall of 60 feet, such a slight loss of head was really immaterial. He had not followed Professor Lea very closely in his remarks about capital costs, but he thought it was almost immaterial whether there was an immediate return on the capital proportionate to the outlay on the first length of main, or the second, or the third. There was less return on capital for the first lengths than for the later ones; but, when the only alternative was an entire new main throughout, of full ultimate capacity, that did not appear a matter to worry much about. He was interested to hear that cross connections had been installed on the Bombay waterworks; it went to show that cross connections, in themselves, were not absolutely original. He had known of the cross connections on the Derwent Valley works, and had been indirectly in communication with Mr. Whiteford. The second main on the Derwent aqueduct had not yet been laid, and that was probably the reason why he happened to be the first to give a description of the effect of cross-overs. With regard to Mr. Lowcock's remarks, a good deal of water could be got through a 6-inch main if enough head were given. As to "guessing," if cross-overs were adopted, as far as the aqueduct was concerned there need be no guessing. The existing condition of affairs, being known, could be met at once, and it was possible to follow the growth of demand as it actually occurred. With reference to Mr. Maddocks's remarks, the formula given in the Appendix was 
for cast-iron mains. It might be proved that there was not The Author. sufficient justification for it, but he had adopted Mr. Barnes's formula because he believed he had good grounds for his faith in it. The 60-inch main to which Fig. 6 related was a reinforced-concrete main, and he had used a formula applicable to a concrete main.

\section{Correspondence.}

Mr. W. Blackadder remarked that the Author had developed Mr. Blackand put into practice a result of the general law of flow of water in long pipes in which the head used to generate kinetic energy due to the speed of the water, or in other losses such as those of valves or. cross-overs, was negligible in comparison with frictional losses. The fact that a Venturi meter (which might constrict the area of flow to one-sixth of that of the main pipe) did not materially affect the rate of discharge in a long pipe (of length equal to 10,000 or more diameters) depended on the same principle.

The Author mentioned that the results expected were realized in practice. Such estimated results could be relied on to be much more in accordance with experiment than in the case of estimation of the delivery of a new untested pipe: for comparative results only were being dealt with; the friction factor, which caused discrepancies between calculated and test results, cancelled out. The powers of speed of flow and of hydraulic mean depth assumed in any formula affected the calculated results, but not to the same extent as the friction factor did. Of course, in all such cases it was presumed that the loss of speed-energy at the cross-overs was negligible, in comparison with friction losses.

The Author showed the many advantages of the system of crossovers and of gradual pipe-duplication for increasing delivery. One point, however, that might be mentioned was that, while the effective length of single main (and so also the effective length of the loops in the case of looping a pipe for increased supply) might, as mentioned on p. 35, be made up of any number of separate lengths, yet the number of these separate lengths should, as far as possible, be. reduced to a minimum. For at each cross-over (or junction) head was lost, and the cumulative effect might appreciably alter the flow from that estimated, especially in the case where the crossovers were of smaller diameter than the main pipe. 